\title{
The Impact of Technological Development on Contemporary Media
}

\author{
Ziqi Yan \\ Chengdu Railway Middle School, Chengdu, Sichuan Province, China. \\ 610041,yzq2640635480@163.com
}

\begin{abstract}
With the development of technology, the arrival of big data has brought great conveniences to people's daily life. The wide application of $5 \mathrm{G}$ has also brought unprecedented development opportunities to the contemporary media industry. Almost everyone cannot live without technology. Therefore, the paper focus on the impact that technology has brought to contemporary media. In order to improve the accuracy and credibility of the article, the author conducted a questionnaire survey on the Internet when referring to official data. This paper will evaluate the influence from a subjective perspective. It will discuss the merits brought by technology from three aspects: convenience of life, employment forms and cultural transmission. Besides, this will analyze its disadvantages from three aspects: pan-entertainment, spreading false information and leaking personal privacy. From the conclusion of the article, the effects of technology do have both pros and cons. While the public enjoys the preferential treatment, they are also inevitably affected by its negative effects. The public should assess these effects from a subjective perspective. The media industry needs to consider social responsibility as well as economic interests. The media industry supervision department should make some improvements and positive adjustments based on user feedback. Also, the relevant departments are supposed to strengthen supervision and stop the illegal behavior and punish it in time.Last but most importantly, the development of the contemporary media industry needs to rely on the power of morality.
\end{abstract}

Keywords: technology, contemporary media, social media, mass communication

\section{INTRODUCTION}

The advent of communication technology brings a great threat to the development of traditional media. People no longer just rely on newspapers, radio and news channels to get information, but are more willing to learn through new forms like short videos. As M.Brown said, communication technology brings people closer to the news for education, entertainment and information,etc[1]. Faced with big challenges, many new media have emerged with the help of big data. It cannot be denied that new media truly bring a number of benefits, but it also exposes some problems. The pan-entertainment of media has caused a great negative impact on the growth of teenagers, which will lead them to form a wrong outlook on life. Long term exposure to vulgarity also leads to their lack of faith. Moreover, the leak of personal privacy is also one of the issues that reflect. The paper aims to guide the public to judge the impact of media on their lives correctly. At the beginning of this paper, the author will introduce its advantages and disadvantages from diverse areas. Then, the paper will give some solutions and advice based on its problems. Finally, the paper will predict media's future development, providing reference for the industry. Through this way, people can call on netizen and relevant departments to join hands to resist the spread of negative influence and strengthen the media's sense of responsibility and legal awareness. Besides, the paper will predict media's future development, providing reference for the industry.

\section{ADVANTAGES THAT CONTEMPORARY MEDIA BRINGS TO LIFE}

\subsection{Employment diversity--- Wanghong}

Wanghong, which means Internet celebrity. They are the persons who rely with the help of social media to make money by posting pictures, videos or live streams and has lot of fans. "celebrities" first appeared in the 19th century during the democratic culture and the 
discourse practice in the public sphere as well as the rise of the culture industry and mass audience[2]. Celebrities can be produced, consumed, admired and adored[3]. The perfect celebrity image needs the participants of celebrity industry[4]. Obviously, the emergency of Internet celebrity has spawned new industries and promoted the diversification of employment methods. Providing a way for many people to earn their living in a highly competitive environment for jobs.

\subsection{Affecting the obtaining way of information}

In daily life, almost everything can be done with the help of contemporary media apps. If someone wants to travel, he can use Google search software to search for local attractions and travel recommendations. If someone wants to rent a house, he can search on Airbnb or Xiecheng APP. There are many things in daily life that can be done through media apps. According to the survey, predicting China's online travel booking usage will reach $35.2 \%$ in 2020[5]. Some online booking platforms do bring various benefits to people's daily. Wherever traveler goes, he just needs a phone or computer to book a hotel. And usually, the prices are often cheaper online than in real life. What is more, the mobile payment rate in China is $71.4 \%, 2.7$ times higher than that in Korea[6].

\subsection{Promoting cultural communication---a case study of Tiktok}

Contemporary media have has profound impacts on the modern society. People's daily life is also inseparable from mach well-known software, like Facebook, Tiktok, Instagram. And Tiktok' market penetration rate had reached as high as 14 percent as of February 2018, meaning 14 out of every 100 internet users are Tiktok users, and the date is still growing[7]. Not only does Tiktok have a huge user market, but it also has a central impact on students. Therefore, actively seizing this position can use the advantage of the government to spread high-quality content as well as enable students to accept cultural influence subtly. Through this way, students make the most of the advantages of Tiktok, helping them form the right values and develop good habits of using media apps. The National Museum of China registered a Tiktok account to help more young people feel the charm of culture through entertainment. This method can guide young people to establish correct views on history, nation and culture with the help of Tiktok., being worthy of promotion[8].

\section{DISADVANTAGES THAT CONTEMPORARY MEDIA BRINGS TO LIFE}

\subsection{Pan - entertainment that causes bad influence}

As the art writer Hauser said: "Entertainment, relaxation, aimless play is an indispensable part of life. Psychologically, this is necessary to maintain high energy, stimulate and enhance activity"[9]. The prosperity of entertainment culture, on the one hand, is because people's demand of enjoyment is generally higher. On the other hand, due of the great richness of media products, there are more entertainment ways for people and the scope of entertainment is much more than any previous period. People's pressure, emotion and desire are released in entertainment. Entertainment and youth development are also inseparable according to Linda Caldwell, an American professor[10]. People spend a lot of time on social media every day. The number of myopic people in China is nearly 400 million, among which 270 million are teenagers, and the trend is on the rise[11]. Part of the reason is the excessive use of eyes during study, and the other part is the excessive use of electronic products. It has a huge negative influence for teenagers, which not only affects their eyesight and physical health, but also makes them addicted to media apps. As the "cultivation theory", said the mass media always have a specific impact on the audience. For example, audiences exposed to a lot of TV violence are far more likely to engage in violent behaviors than others. Also, some inappropriate behaviour will have a bad impact on the growth of teenagers. It also shows the two sides of the media[12].

\subsection{Spreading fake news or messages will cause panic}

From a survey conducted by the author, 95 percent of users have received fake messages and news on contemporary apps[13]. The senders usually said"Please actively forward the video when you see it" or "Please share the video with your families and friends". As a result, fake news is spreading faster and more widely with the help of the Internet, causing panic and anxiety among the public. Until the official crackdown, many people have been cheated(maybe have leaked personal information). False and untrue reports will not only damage the credibility of the media, but also will reflect the irresponsibility of the whole press to the audience. Fake news is often heard, but rarely punished, which encourages some people to get away with it. If the related industries do not operate properly and the relevant department do not strictly supervise, it will eventually lead to social disorder, because people can not tell the true from the false. 


\subsection{Divulge personal privacy}

Solove, who is a well-known professor in the law of privacy, said that it can not be possible to live without any record being taken from us[14]. With modern technology, it is quite easy to get information from anywhere about anyone. People often encounter situation like this: when people log on to a platform or register as a user, they need to input your name, phone number, ID number, residence,etc. If people do not enter the required information, they will never be able to use the software. So people are exposing detailed personal information invisibly. You have probably been in this situation: you have recently decided to buy a car or a house, and once you have inquired via phone, text, website,etc., you will be bombarding yourself with messages trying to sell you a car or a house over the next few days. This is a typical manifestation of personal privacy leakage. Sometimes people feel like you are being monitored, but "monitored" does not mean that you are being watched all the time, but that your information obtained about us is recorded( e.g. electronic photo album, booking the tickets, Air pay, etc.). Especially with the help of computer, everyone's information is stored in a database, and the collected information can be transferred instantly.

The impact of media on ordinary people may not be huge, but for public figures it has a vast influence on their lives. Once a celebrity is caught in a scandalous paparazzi photo, information about them( who in the photo, where they were taken, when they were taken, and even how they behaved) will spread around in Internet. The cruelest thing is that when the private lives of public figures are exposed, they are always attacked and commented by a netizen to varying degrees. That is because in the mind of the public, celebrities must be perfect, the slightest shortcoming is not allowed. Some stars even need to use money to negotiate with people for private information. Public figures can face serious challenges with their personal information being leaked.

\section{SOLUTION}

\subsection{Correctly guide the development direction of contemporary media industry}

Based on the above analysis, effective measures must be taken.

To begin with, what the people should do is to guide the development direction of contemporary media industry correctly, so as to realize the unity of economic and social benefits. Mass media, as a kind of media that conveys information, its important function of information dissemination and public opinion guidance should be fully brought into play. If it is dominated by market blindly, it will weaken its social education and have a negative impact on the whole social atmosphere.
But the mass media, as a tool for spreading information, do not have any impact on its own. What really affects the public is what it delivers[13]. Although the influence of mass communication is permeable, widespread and open, users can also optimize the media content by controlling source of mass communication, namely the contemporary media.

\subsection{Essential to strengthen supervision and management of the media}

Besides, it is also essential to strengthen supervision and management of the media. For one thing, the government needs to formulate special laws and regulations in line with the characteristics of media's development to improve the legality of this industry. In particular, laws on teenagers should be improved to give full play to the laws authority and compulsion. For another, the relevant department needs to regulate the current phenomenon of pan-entertainment of media and screen media content to prevent excessive entertainment and vulgarization.

\subsection{Establish correct moral values}

Last but not least, to promote the healthy development of the media industry, it is also necessary to rely on the power of morality, which means to advocate media workers to take active part in social responsibilities. The communication practice of the median pursues social justice based on the specific social morality, and the moral concept should occupy a dominant position in the public reports of the media. As early as the 1920, American communication scholars put forward the theory of "social responsibility", which emphasized that the media should assume corresponding social responsibility on the premise of pursuing the freedom of the press. To strengthen the social responsibility of the media, the first one is strengthen the education professional ethics for the media workers. Secondly, the media industry should adhere to the correct guidance of public opinion. The mass media should set up the correct communication concept, actively disseminate advanced culture and thought, guide the social atmosphere with healthy and meaningful media content, and realize the social value of the media.

\section{CONCLUSION}

Based on contemporary media's diversities, all the people should evaluate the technological development of media from a subjective perspective. While enjoying the benefits brought by the media, people should not ignore its disadvantages. Like the negative effects of pan-entertainment on people, spreading fake news and divulging personal information. However, some useful advice can release users' worries about its drawbacks. 
The government should properly regulate and guide the media industry, such as by virtue of moral force. In the process of investigation, the sample size is too small and the form is single due to some limitations, so that the data obtained is not universal. In future research, the author will use big data for systematic analysis to get more accurate conclusions. In the end, the author believes that the future media industry will be more intelligent and humanized, in order to fit the trend of society and gain more support from people, helping the media industry develop smoothly.

\section{ACKNOWLEDGMENT}

First and foremost, I would like to show my deepest gratitude to my teachers, who constantly provided me with valuable and professional guidance in every stage of my writing. What is more, I would like to say thanks for my friends and families for their encouragement and support. Without all their heartfelt help, I could not have completed my thesis.

\section{REFERENCES}

[1] M.Brown. Bringing people closer to the news. Brandweek, October 2, 2000, p.26

[2] Marshall P D. The promotion and presentation of the self: Celebrity as marker of presentational media[J]. Celebrity Studies, 2010, 1 (1) : 35-48.

[3] Cashmore E, Parker A. One David Beckham? Celebrity, masculinity, and the Soccerati[J]. Sociology of Sport Journal, 2003,20(20): 214-231.

[4] Gamson J. Claims to fame: Celebrity in contemporary America[M]. Berkeley: University of California Press, 1994

[5] China's online travel booking usage, data.iimedia.cn 2020.08.06

[6] The mobile payment rate, Yonhap news Agency 2019.09.24

[7] Investigation on the number of Tiktok users, JiGuang big date https://t.qianzhan.com/int/detail/180313-46c672f2. html.

[8] Seven major museums collectively enter Tiktok, new way show national treasure to win new audiences. China News Network http://finance.ifeng.com/a/20180516/16282960_0.s html.

[9] Arnold Hauser wrote, Yanan Ju translated :Art and Sociology Shanghai: Xuelin Press, 2009 edition, p231

[10] Linda Cade wrote, Huimei Liu, Pin Sun translated: Entertainment and youth development, Zhejiang: Zhejiang University Press, 2009editio, p189

[11] The number of myopic people in China, China Vision Data Statistics Network, January 1, 2019

[12] Bergner' theory of cultivation, 1960.

[13] Investigation on the use of Tiktok, Wechat small program, questionnaire star.

[14] Daniel J. Solove Understanding privacy, 2011. p. 2 